\title{
Harnessing latent sustainability: a postcolonial perspective
}

\author{
S. Sharma ${ }^{1}$, S. M. Singh ${ }^{2}$ \& I. Kularatne ${ }^{1}$ \\ ${ }^{1}$ Otago Polytechnic Auckland International Campus, New Zealand \\ ${ }^{2}$ Aubade New Zealand Ltd, New Zealand
}

\begin{abstract}
In this paper, we have introduced a new form of sustainability that is holistic. It is based on a belief that promoting economic sustainability in the value chain can help in attaining economic, social and environmental sustainability. Hence, we argue that focussing on economic sustainability is paramount for any business aiming to attain long term sustainability. Our proposed theory is based on a single case study of an Indian Multinational Corporation (IMNC) Aubade New Zealand Ltd (ANZL). We have applied a postcolonial perspective to analyse the international business practices of ANZL. This helped in illustrating the presence of hybridity amongst the senior management and therefore they adopted a new strategy of backward integration. The strategy has assisted them in gaining the trust of the value chain members in New Zealand and in India. It is also helping in delaying the deskilling process in India. In fact, the strategy of backward integration is serving ANZL in attaining economic, social and environmental sustainability.

Keywords: latent sustainability, postcolonial theory, hybridity, international business, innovation, strategic management, critical management research.
\end{abstract}

\section{Introduction}

The strategic importance of sustainability for the growth and survival of a business enterprise is a widely accepted concept. But, what sustainability means remains contestable. Most managers believe that it is something external to their business operations and therefore to attain sustainability, external assistance would be necessary. This is the fundamental reason why they prefer to outsource to a sustainability expert. The trend is becoming more common in the emerging 
economies such as India where corporations are keen to appoint an overseas expert for the job.

We are against such superficial engagement and therefore we have applied a postcolonial perspective to show that sustainability is an emergent concept rooted in the cultural practices of an organisation. We show this by analysing the discourse and daily business rituals of the staff members of a New Zealand based Indian Multinational Corporation (IMNC). Our aim is to introduce a new form of sustainability that is hidden. This form of sustainability is not easily identifiable because it originates from the involuntary actions of managers. It is also difficult to control. Our aim is to highlight this fact with the help of a single case study so that the managers are able to nurture these qualities to gain from them.

One of the main contributions we make to the existing scholarship on sustainability is that we highlight the limitations of the existing sustainability models. These models primarily developed in the West are based on a Eurocentric perspective on sustainability that promotes a binary system. The sustainability model we have developed challenges binaries such as the West/the East and modern/traditional. It helps to show the interconnectedness of global trade that produces hybrid forms. These forms challenge the ideology that prioritises the West over the Rest (Kothari [1]).

This is extremely important also from the trade relationship perspective between New Zealand and India. At present, there are number of IMNC in New Zealand. But, their contributions to New Zealand economy are not fully recognised. A fine grain postcolonial analysis helps to show that the problem is deep-seated and has its roots in an ideology that not only promotes racism and antagonism towards the migrant communities (Leckie [2]), but, also, it results in their marginalisation due to lack of career opportunities (Pio and Essers [3]). In fact, it is one of the main reasons why a large majority of Indian migrants start business operations in New Zealand in the first place (Pio and Essers [3]).

The sustainability model that we propose, based on our holistic approach to sustainability, holds the propensity to engage with some of the issues that we have discussed. Another important aim of this paper is to map the co-existence of the economic, social, environmental sustainability and challenge the perspective that shows that they are in conflict with each other.

In sum, our aim is to show that another form of sustainability is possible. Organisations must continue to focus on their primary goal of attaining economic sustainability and social and environmental sustainability will emerge from the process itself. In the following section, our aim is to familiarise our readers with the postcolonial theoretical framework required to critique the basic premise of some of the existing sustainability models. This helped us in developing our own sustainability model.

\section{Postcolonial theory}

One of the reasons for selecting a postcolonial theoretical perspective is that it helps in understanding the process that artificially maintains the distinction between the West and the East. It assists in creating a much deeper 
understanding of colonisation's maintenance mechanisms that requires the creation of the East/Other so that the superiority of the West/Self can be established (Kothari [1]). One of the major contributions of postcolonial perspective is that it helps in decolonising traditional knowledge by deconstructing the Western discourse that privileges conventional science and presents it as obvious and rational (Briggs and Sharp [4]).

In the context of international business and management the perspective will help to show that Western management practices are not superior and the distinction between the Eastern and the Western management practices has been artificially created. Also, these discourses have a tendency to place all the nonEuropeans into a single category as Other, thereby ignoring the multiplicity of their subjectivities and voices (Raghuram and Madge [5]).

Hence, it is critical 'to situate the particular experiences of colonialism in a precise historical and cultural context' (Morton [6]). As it assists in exposing the existing binary logic and helps in deconstructing the management discourse that produces it (Banerjee and Prasad [7]). This is required because the logic helps to promote racial stereotypes which for example may suggest that Indian migrants are incapable of taking up managerial positions and senior management roles in New Zealand because they are inferior to the Westerners (Pio and Essers [3]).

Leckie [8] shows that sometimes even the elite cannot avoid racial stereotypes by quoting the example of Anand Satyanand former GovernorGeneral of New Zealand who is a New Zealand born Fiji Indian. One of the television presenters Paul Henry criticised him for not looking like a New Zealander and therefore may not be worthy of holding a high office.

In short, postcolonial theory constantly links the present with the colonial past to draw similarities between them, primarily to make us aware of the prevailing injustice today and the ways in which it can be opposed. We argue that a postcolonial analysis greatly enhances our ability to understand and draw out the subtle similarities between the colonial and the postcolonial times and, consequently, illustrates the continuance of injustice because of the presence of neo-colonial elements present in the society (Banerjee and Linstead [9]).

One of the classic example of that is the assumption that technology and processes developed in the West are superior and of universal significance. It can be therefore easily used in the East without making any major changes to it.

However, Das [10] argues that in a country such as India where labour is inexpensive and in abundance, the adoption of new technology is slow. The West has always tried to show that because of this reason India is backward. We challenge such comments and show that the reverse is true with the help of the case study. Also, the rate at which the emergent economies such as India are growing, it will result in an irreversible damage to our planet and will speed up the global warming process. Therefore, new and greener technologies developed in the West must be exported to India to save the World from disastrous consequences.

Our analysis challenges such claims by showing that the very premise of such arguments is baseless. It is based on an artificially created superiority in which the Other is always assumed to be inferior to the Self. Joshi [11] argues that the 
climate change debate has shifted in favour of India and finally it seems that Indian bureaucrats have succeeded in convincing the Western countries that India has a right to develop just like they had in the past and therefore developed countries must try to reverse the process of global warming by reducing their material consumption.

Academics working in the area of innovation and development argue that may be it is time for the West to learn innovation techniques from the East (Agnihotri [12]). Agnihotri [12] is a keen promoter of the reverse innovation. Therefore, she argues like so many other academics have done before her that frugality in research and development can help save millions of dollars. It can assist in producing products and services locally. However, the products still can have a global appeal. For example, Mitticool - a refrigerator made of clay running on water without electricity was developed by a pottery maker from rural India in order to help the local community, now is being exported to Australia (Mitticool [13]).

It is significant but not incomprehensible. There are several examples such as this and one of the main reasons for this is the presence of hybridity amongst Indians. One of the proponents of postcolonial theory Bhabha's [14] contribution is significant in this regard because he explains that the interaction between the Europeans and the non-Europeans creates hybridity amongst both. During the sixteenth century, when the British came to India they saw that the Indian textile industry was well established and they were the major exporters of textiles made of cotton (Das [10]).

\section{Case study}

\subsection{Commodity trading phase}

Aubade New Zealand Ltd (ANZL) is an Indian multinational corporation (IMNC) located in Auckland, New Zealand. The core business of ANZL is to export logs to emerging markets such as India. The company operates in a highly competitive and price sensitive market. ANZL parent company - Mayar group ventured into New Zealand in 1999 as a commodity trader and exporter of logs to India, but found it challenging to operate in a highly price sensitive market.

Also, due to the lack of acceptability of a new species, the Radiata softwood pine in the Indian timber trade with a strong preference for native hard wood their chances of succeeding in the Indian market were further reduced. During this period, ANZL was buying logs from the open market for export to India. Their risk as an exporter was low but their control over their operations was also low.

\subsubsection{Credibility issues}

Rather, it became almost impossible for ANZL to establish its creditability in the market being a trader. The situation became so bad that Mayar Group decided not to continue their market forays in that form and manner and withdrew from the market to reformulate their business strategies. 
In 2012, Mayar Group re-entered the market and hired a business manager and perused a port based (at Wharf gate) procurement strategy through prefunding small scale suppliers. However, insufficient scale and lack of creditability rendered the model ineffective. The structure was disbanded by the group and the model discontinued.

\subsection{Long term commitment strategy}

A year later, Mayar group operationalised ANZL under the stewardship of Country Manager Satinder Mohan Singh who embarked on a new strategy of acquiring plantations. Satinder is from the state of Punjab in India. After completing Bachelor in Engineering and Masters in Business Administration in Punjab, he worked for several years in commodity trading in India before moving overseas. Satinder has an extensive overseas experience in the forestry and related industry and commodity trading.

\subsubsection{Hybridity}

Satinder has worked in number of countries around the globe. Particularly, his experience in Panama, Ecuador, Ivory Coast, Ghana, Senegal and New Zealand created hybridity in him (Bhabha [14]). One of the main reasons for this had been his continued interactions with local government officials and contractors in these countries. He had to negotiate deals with them in a completely different way that he was used to in his country.

However, one thing that was common amongst the countries that he operated was their colonial background. But, as several scholars recognise that each experience of colonisation was much different from the other (Raghuram and Madge [5]). Satinder had to constantly modify his approach and the hybridity that he gained from all his previous experiences helped him to open the third space. The third space, according to Bhabha [14], creates a possibility of gaining agency.

\subsubsection{Agency}

In recent times, several scholars have made an effort to understand the process whereby migrants from the East are able to gain agency in the West because of their entrepreneurial efforts (Pio and Essers [3]). Satinder was able to gain agency by acquiring harvesting rights for Whataroa Forest for 10 years by entering into a deal with the New Zealand Forestland Ltd (NZFL). Officials who had approached him with the proposal to jointly make an offer to the seller of the forest. The NZFL was interested in the land and Satinder as a Country Manager of ANZL in the ownership of trees present in the forest. It was a win-win situation for both of them. The forest had been in the market for the last 9 years that is since 2004. But, no one was interested in buying the forest because it was not economically viable for investors catering to the local market. However, Satinder saw the potential of exporting the logs to India and therefore went ahead with the deal. 


\subsubsection{Challenging the neo-colonial discourse}

There is a general perception in New Zealand about the IMNC that they are only interested in profits and transferring the funds to their home country. However, ANZL's contributions to the New Zealand economy show that the claim is baseless and therefore it is important to delegitimise such neo-colonial discourses. Banerjee and Linstead [9] draw our attention to the omnipresence of neo-colonial element in the West. They are particularly critical of the business organisations engaging with the indigenous peoples in Australia because they are not confident if the projects developed by these organisations actually benefit the marginalised.

This is important because most people in the West trust local businesses more than businesses established by migrants. One of the main reasons for this is that they assume that the local businesses always benefit the economy. Similarly, in New Zealand most people assume that New Zealand organisations are the ones which are truly dedicated to the cause of growing the New Zealand economy. The media also supports such assumptions and mostly neglects the contributions of the migrants. In fact, ANZL activities are equally beneficial for the New Zealand economy because there is no demand for a low grade quality wood in local New Zealand market. According to the Operation Manager of ANZL, Andrew Beach, the logs that they are exporting to India are bi-products of a process required to extract pruned quality softwood for the local New Zealand market. Therefore, it has no value in the local market. But, because the biproduct can be exported to countries such as India at a profit, the extraction of pruned quality softwood for the local New Zealand market becomes a viable option.

Not only this, the strategy to export unprocessed logs makes it feasible for the buyers in India to process logs in semi-automatic saw mills in which semiskilled and skilled workers are able to recover 92-93\% softwood fibre. A much higher yield with their human intelligence, skill and effort that is unthinkable in an advanced country such as New Zealand where the downside of the technological advancement is that it results in an exponential increase in wastage. However, it is a challenge to make New Zealanders understand that it is better to process logs in India instead of adding value to the logs in New Zealand before they are exported to India.

One of the key contributions we have made is that we have created avenues to change the mind-sets. Our aim is to challenge the assumption that without the use of the so called greener technologies developed in the Western countries such as New Zealand, India cannot engage in sustainable business practices. Therefore, we believe that it is our duty to highlight the problems associated with the framing of environmental and social and cultural issues in the West concerning developing countries such as India which influences the development of international business theory.

\subsubsection{Mimicry}

It can be argued that Satinder had always worked in positions of authority and therefore he would have never experienced marginality in anyway. Interestingly, 
Satinder too resisted the idea that his identity was formed because of some postcolonial influences that he had during his work. However, in our discussions it became apparent that he consciously mimics and therefore prioritises the Western perspective and way of organising. But, his management and leadership style is based on involuntary actions that seamlessly combine the Western and the Eastern management style. Eventually, he was able to understand that his hybrid identity is the source of his agency and a long term strategic advantage while operating in foreign and hostile environments. Therefore, he believes that it is in the best interest of all the stakeholders in the value chain that the logs from New Zealand must be exported to India, unprocessed to be later processed at the semi-automatic saw mills there. Some of the politicians with the support of some media channels argue against it for mainly two reasons. First, it results in job loss in New Zealand and second it leads to the exploitation of workers by the saw mill owners in India.

\subsubsection{Benevolence}

The argument that is generally made is that the workers in India work in appalling conditions particularly in the saw mills near Kandla port in Gujarat. It is one of the busiest ports in India and it comes as no surprise that the majority of the vessels carrying unprocessed logs end up there only. It is important to acknowledge that the issue they are raising has some basis to it. But, the way it is presented clearly shows the paternalistic attitude of the West and their complete disinterest in trying to find a solution for the problem in consultation with the workers. What is needed is an engagement with the workers in these saw mill and attempts must be made to find out what they actually want. Joshi in her thesis has applied Spivak's cultural analysis of one particular intervention of the British officials during the colonial period in India (Sati) to show that numerous problems can emerge when a top down approach is adopted to solve issues without understanding the cultural and social implications associated with the issue (Joshi [15]).

\section{Discussion}

New Zealand government wants to increase exports. One of the ways to achieve this is to export value added goods instead of raw material. The cost of processing the logs is high in New Zealand in comparison to developing countries such as India. Developed countries such as the U.S. and New Zealand are finding it difficult to cater to the needs of their customers and they are losing business to developing countries suppliers who are able to supply non-standard sizes because of the way they process wood as we have discussed earlier. The only option is to find suitable processing zones and identify stocks that suit the resources and also to try to find ways to meet the demand of high end customers (Bayne [16]). In fact, this is exactly what ANZL is doing. This was possible because of their strategy of backward integration. Therefore, the New Zealand exporters must try to find innovative ways of remaining competitive. They should not stop exporting unprocessed logs for now. Also, New Zealand media 
should refrain from superficially engaging with the subject of the working conditions in saw mills in India.

Rather, they should directly ask the saw mill workers in India what they think about their wages and working conditions. Inexpensiveness and abundance of labour is a competitive advantage for the Indian saw mills. A large majority of workers in Kandla one of the busiest port in Gujarat state in the Western India are from rural background. They migrate to places such as Kandla for work because this is possibly the only way to get out of the poverty trap. Raghuram et al. [17] show that the growth in Asian countries such as India has happened mainly in the urban areas and the rural areas remain neglected.

A large majority of workers have to start as unskilled workers and eventually they gain skill and experience and are able to find employment in semiautomatic saw mills as semi-skilled and skilled workers. These mills exist only because of these workers. In developed countries such as New Zealand, fully automated saw mills were introduced, because of the shortage of labour. These mills are perfect for the New Zealand domestic market where demand is for the pruned quality of wood. But, these mills are not suitable to process low grade wood for export because it is not financially viable. Markets such as India are extremely price sensitive.

Hence, Satinder uses creative ideas to develop new ways of operating. He is able to make use of a unique opportunity to export logs of wood to India because of the rapid development is happening in India and also because the Government of India (GOI) has banned the felling of tree to replenish the forest because they had reached dangerous levels of deforestation (The Hindu [18]). By exporting wood that has been harvested in a most sustainable way following strict New Zealand government regulations and guidelines, he adds a new chapter in sustainability.

The sustainability goals, though unintentionally, are attained at the point of origin and by strategically organising processing of logs in India mainly for the maximization of profits, further sustainability is achieved by increasing the waste reduction. Furthermore, by accidently promoting work enrichment amongst the workers engaged in the processing of logs in India, another element in the sustainability circle is added.

This was not possible for him several years ago when he was working for a different organisation in Africa. However, the lessons that he learnt during his tenure in Africa prompted him to move to a new and developed country such as New Zealand in place of the underdeveloped or developing African countries. The new opportunities brought a new way of thinking and operating and finally he was able to do what was not possible earlier.

Satinder takes pride in his knowledge of logistics. He argues that in spite of burning fossil fuel to ship the logs by sea to India. The operation is not completely unsustainable given the social and cultural benefit that flows from it. In fact, if we view this from a pragmatic perspective, we will realise that there is actually not too many options because the ban GOI has placed on felling of trees in India and because of which the logs have to be imported from overseas. A possible alternative is to import from Malaysia in place of New Zealand because 
of its geographical proximity to India. But, again, there is one major issue is that the way wood is harvested in Malaysia and logging is done. It is extremely exploitative and creates all forms of marginality for the workers.

In this paper, we show that there is a lot to learn from Eastern culture and sustainability. Most indigenous cultures and Indian culture is not any different because they adopts a more holistic view to sustainability. These cultures view sustainability as just a small part of the whole which cannot be removed and therefore introduced separately in case it is missing. This contrasts the way sustainability is viewed in the West as something that can be added on later as per the requirement.

More recently, the indigenous scholars in the West have tried to weave the Western and Eastern perspectives on sustainability together. One such paper written in 2013 by a New Zealand researcher highlights the importance of merging the both the perspective instead of prioritising one over the other.

However, in our paper, what we are proposing is that the two perspectives already coexist and therefore there is an urgent need to identify and acknowledge this union. Our claim is firmly based on the fact that most cultures that exist today are hybrid and that the cultures always evolve with time. Emergent countries such as India have a history of colonisation and conquest.

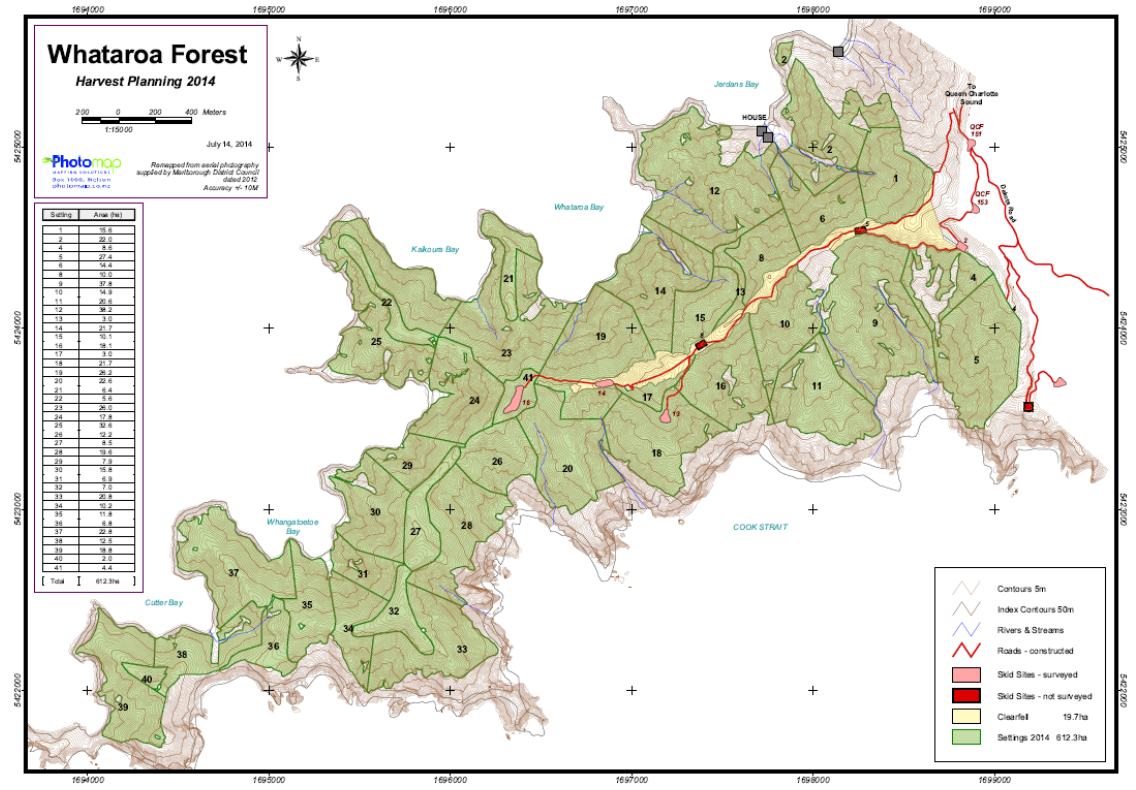

Figure 1: Whataroa Plantation Forest map. 


\section{Methodology}

The primary data for the case study was collected by the first author with the help of eight in-depth expert interviews with the country manager of ANZL Mr Satinder Mohan Singh, who is also the second author of this paper. The narrative style was used by him to share the information (Pio and Essers [3]). Each interview was approximately one hour long. The first interview was conducted in February 2015. The data collection lasted for three months. The interviews were generally conducted on Monday afternoons. Also, it was based on the availability of the participant because he frequently travels within New Zealand and overseas.

Notes were taken during the interview on paper in the beginning and later on a laptop computer. Once the Permission to participate in the research and to share information for the research purposes was obtained by the second author, he became much more relaxed and was ready to share company's information more freely. This made analysing the company documents easier. It was critical for the development of the case study.

The information collected was later validated by informally talking and interviewing other company staff members and by analysing company documents and related secondary material. After each interview, thematic analysis was conducted by the first author to analyse the data. This helped in the development of theory. The interviews were stopped once the saturation was reached which means no new information was emerging.

A single semi-structured interviewed was also conducted with the Operations Manager of ANZL Andrew Beach when he visited Auckland in April 2015. This was very useful because several new things came up during our discussion and was an opportunity to gain a different perspective.

The first author has known Satinder for last two years. He met him in a conference and has kept in touch ever since. In the middle of January 2015, the first author discussed with Satinder about the paper that he wanted to write on sustainability and requested him to be the second author.

One of the reasons for co-authorship and the use of postcolonial theory as a methodological framework were to develop theory based on a discourse that is created through dialogue between the researcher and the researched and not controlled by either of them. Also, the distance between the researcher and the researched was reduced significantly once interviewee became the co-author of the paper. However, it was not completely eliminated.

\section{Conclusion}

In this paper, based on a single case study, we have shown that economic sustainability drives environmental sustainability. ANZL collaborated with NZFL purely for economic reasons. It made sense to export the lower grade wood to India because there was no market for the lower grade wood in New Zealand. Also, this helped NZL to extract the pruned quality wood for the local market. In fact, without exporting the bi-product which is the low grade wood, 
pruned quality wood for the local market cannot be extracted as we have shown earlier.

Harvesting Whataroa Forest is an economic decision for ANZL. But, there are some environmental benefits too. As we have explained in the discussion section, the scientific requirement for harvesting the plantation forest. Once the forest reaches maturity, it is in the best interest of everyone to harvest the forest. Also, processing of logs in India is again an economic decision. But, it is helping to slow the de-skilling process in India and therefore there are some social benefits too.

We have also shown that the protectionists discourse based on racism has no scientific bases. New Zealand cannot afford to process low grade wood that is being exported to India and China. Rather, the focus should be to develop New Zealand as a knowledge economy and create jobs in that sector.

Finally, no matter how important it is to harvest the plantation forest for environmental reasons. The speed at which the forest would be harvested depends on the demand and at present the demand is low because of the slowing down of the Chinese economy. It is also affecting the Indian market because traders have started exporting logs to India in place of China. The Indian timber market is much smaller in comparison to China and excessive supply is dragging the price down.

\section{References}

[1] Kothari, U., Feminist and postcolonial challenges to development (Chapter 3). Development Theory and Practice - Critical Perspectives, eds. U. Kothari \& M. Minogue, Palgrave: Hampshire, pp. 35-51, 2002.

[2] Leckie, J., The southernmost Indian Diaspora: From Gujarat to Aotearoa. South Asia: Journal of South Asian Studies, 21(s1), pp. 161-180, 1998.

[3] Pio, E. \& Essers, C., Professional migrant women decentring otherness: a transnational perspective. British Journal of Management, 25, pp. 252$265,2014$.

[4] Briggs, J. \& Sharp, J., Indigenous knowledge and development: a postcolonial caution. Third World Quarterly, 25, pp. 661-676, 2004.

[5] Raghuram, P. \& Madge, C., Towards a method for postcolonial development geography? Possibilities and challenges. Singapore Journal of Tropical Geography, 27, pp. 270-288, 2006.

[6] Morton, S., Gayatri Chakravorty Spivak, Routledge: London, p. 113, 2003.

[7] Banerjee, S. B., \& Prasad, A., Introduction to the special issue on critical reflections on management and organizations: a postcolonial perspective. Critical Perspectives on International Business, 4(2/3), pp. 90-98, 2008.

[8] Leckie, J., Anand Satyanand: a prominent son of the Indian diaspora. New Zealand Journal of Asian Studies, 16(2), pp. 31-46, 2014.

[9] Banerjee, S. B. \& Linstead, S., Masking subversion: neo-colonial embeddedness in anthropological accounts of indigenous management. Human Relations, 57, pp. 221-247, 2004. 
[10] Das, G., India Unbound: From Independence to the Global Information Age, Profile Books: London, pp. vii-412, 2002.

[11] Joshi, S., Environmental Justice discourses in Indian climate politics. Geo Journal, 79, pp. 677-691, 2014.

[12] Agnihotri, A., Low-cost innovation in emerging markets. Journal of Strategic Marketing, 2014, pp. 1-13.

[13] Mitticool, http://www.mitticool.in/

[14] Bhabha, H. K., The Location of Culture, Routledge: London and New York, pp. xiii-285, 1994.

[15] Joshi, S., Development and India's climate politics: a postcolonial political ecology of the atmospheric commons, Doctoral thesis, University of Oregon, the U.S., pp. ii-203, September 2011. https://scholarsbank.uoregon.edu/xmlui/bitstream/handle/1794/12030/Josh i Shangrila phd2011su.pdf?sequence $=1$

[16] Bayne, K., Wood quality considerations for radiate pine in international markets. New Zealand Journal of Forestry, 59(4), pp. 23-31, 2015.

[17] Raghuram, P., Noxolo, P., \& Madge, C., Rising Asia and postcolonial geography. Singapore Journal of Tropical Geography, 35, pp. 119-135, 2014.

[18] NGT bans cutting of trees across country; The Hindu, New Delhi, India. November 25, 2014 http://www.thehindu.com/news/national/nationalgreen-tribunal-bans-cutting-of-trees-across-country/article6632787.ece 